a real need for an extension of post-graduate work both in research and in specialised studies in the fields of technology and administration, for established technical staff and executives"; some advanced students might with advantage work in the laboratories of the research associations. These and many other valuable suggestions are ably dealt with by Prof. Robertson in his discussion of engineering as a basis of a liberal education.

\section{National Maps of Britain}

A CIRCUlar from the Ministry of Town and Country Planning directs attention to a new series of maps of Great Britain constructed to illustrate various aspects of national life and resources. The scheme is a development of the idea of a National Atlas originally prepared by a eommittee of the British Association in 1939 and is now under the guidance of both the Ministry of Town and Country Planning and the Department of Health for Scotland. The maps are being published by the Ordnance Survey. All maps are to be on a scale of $1: 625,000$, or about ten miles to an inch, and all will bear the new national grid. Each map will be in two sheets, covering respectively (1) Scotland and the northern part of England and (2) the remainder of England and Wales. Those sheets already published are the base map, land utilization, administrative areas, topography, population density in 1931, types of farming and land classification. Several of these are new compilations. Shortly to be ready are sheets showing population of urban areas in 1938 , roads, coal and iron resources, and iron and steel production. Others in hand include a physical map, with accepted terminology of physical features, grasslands of England and Wales, geology, electricity supply, gas, railways, population changes, various economic maps, and seaports. The price of the published sheets is generally five shillings.

\section{Colorado Beetle in England during the War}

THAT the freedom of the potato crop in England from the ravages of the Colorado beetle during the War was due not to good fortune but to the vigilance of the Ministry of Agriculture is evident from an article (Agriculture, 52, p. 210) describing the infestations that have occurred in various parts of the country in recent years. Since the outbreak at Tilbury in 1933 (which was only the second recorded in Great Britain) a close watch had been kept on potato crops, particularly in coastal areas. During 1936-39 a few beetles were reported in soils along the south-east coast and on ships in port, and, when military traffic across the Channel started, the precautionary measures were intensified. In 1941, however, beetles were discovered at six separate localities in the west of England, three of them being on inland farms in Devonshire. The special methods adopted for exterminating the pest were increased publicity and inspection, precautionary spraying of crops within a five-mile radius of an outbreak, and the restriction of potato growing to fields which had carried the same crop in the previous year. Approximately 30,000 acres of potatoes were inspected, beetles being discovered at five localities in the south-west counties in 1942. One further outbreak occurred in Wiltshire in the following year, and since then no infestations have been reported, though a few beetles were discovered on vessels and aeroplanes of cross-Channel services. The pest has evidently not yet established itself in Great Britain; but growers are asked to keep a constant watch and notify the Ministry at once of any circumstances which arouse suspicion that the beetle may be present. Unauthorized spraying is strongly discouraged as it may cause the beetles to spread.

\section{Use of Fertilizers in Britain}

The need for maximum food production in Great Britain during the War called for the highest efficiency in the use of what fertilizers were available, and it is generally agreed that a drive for still further improvements must be made in the future if agriculture is to be put on a sound footing. In "Fertilizers During the War and After" (Pamphlet No. 13. Bath and West and Southern Counties Society. 2s.), Dr. E. M. Crowther gives a comprehensive and most lucid survey of the subject, which will both be a valuable guide to all concerned with crop production, and also of considerable historic interest. After comparing the pre-war consumption of fertilizers in Great Britain with that of neighbouring European countries and the United States, it describes the war-time rationing scheme for England and Wales, discusses the basis upon which it was founded and shows how the experience from large-scale field experiments has been utilized. It is impossible to give an adequate picture of the range of subjects dealt with, but among the newer aspects mention may be made of fertilizer placement. Results from field trials indicate that labour may be saved and the efficiency of fertilizers increased if small amounts of well-prepared fertilizer are placed in definite positions near the seed at the time of sowing. Another development that may well occur in the future is in the use of standardized com. pound fertilizers, which have proved so successful during the War. As regards the fertilizers themselves, Dr. Crowther considers that the technical efficiency of both making and using phosphate fertilizers needs to be improved, and he puts forward a plea for some revision of the Fertilisers and Feeding Stuffs Act Regulations, so that full advantage may be taken of current and future research.

\section{The Tata Memorial Hospital}

Among the buildings of Bombay the strikingly modern design of the Tata Memorial Hospital for the treatment of cancer and allied diseases must stand out with a distinctness which will direct attention to the beneficence of its purpose. Founded by the trustees of the late Sir Dorab Tata as a memorial to the philanthropy of Mr. J. N. Tata and his two sons, Sir Dorab and Sir Ratan, this fine hospital came into being in 1941 and has issued its first triennial report. Designed and built after consultation with experts from Manchester, London, New York, Cleveland, Paris, Stockholm and Brussels, the hospital is now staffed by Indian surgeons, anæsthetists, radiologists, pathologists and physicists, many of whom were sent abroad while the hospital was being planned and built, to gain special instruction and experience. The result is a hospital which can take its place beside any centre for the study and treatment of cancer, and it is not surprising that its superintendent, Colonel Sir J. N. Duggan, can report that it has, in spite of the handicaps of the war years, gained for itself a fine reputation. Any institution which can achieve, during a war like the one which has just ended, a standard of work like that which is here described, may congratulate itself. Future reports of its peace-time work will be awaited with interest. 